\title{
EXPERIMENTAL STUDY ON THE EFFECTS OF THE OFFSHORE NOURISHMENT USING THE COASER SANDS WITH THE CROSS-SHORE SEASONAL CHANGE
}

\author{
Yoko Shibutani $^{1}$, Yuhei Matsubara ${ }^{2}$, Masamitsu Kuroiwa $^{3}$ and Noriko Yao $^{4}$
}

\begin{abstract}
In recent decades, beach erosions have become severe at sandy beach in the world. The coarser sand nourishment has been noticed in Japan because of the stabilization of the beach coast. However the performance is not clear. Therefor in this study, laboratory experiments were conducted for the beach nourishment using the coarser sand. Through of this experiment, the effect of the coarser sand nourishment was investigated.
\end{abstract}

Keywords: beach nourishment; laboratory experiment; cross-shore sand

\section{INTRODUCTION}

In Japan, although the beach nourishments using the coarser sand have been carried out in the coastal zone as an advanced defense work, the mechanism of the stabilization of the beach face has not been clarified. At Yuyama Coast (Tottori Sand Dune Coast), in Tottori Prefecture of Japan, the coastal erosion has been serious problems too. Tottori Sand Dune Coast is a sandy beach with a length about $8 \mathrm{~km}$, facing Sea of Japan. At western part of the coast, Tottori Port and Sendai River are located, Shiomi River and Iwado fishing port are situated at the other side of the area and Tottori Sand Dune, which is the largest coastal sand dune in Japan, located at the midpoint. The Coast started eroding around 1940s, and structures were constructed. On the sandy beach the coastal erosions become more serious. On the other hand, the port and river month have been accumulated the sediment. Consequently, the constructions caused by uneven distribution of sedimentation. Therefore beach nourishment project has been carried out for against erosions since 2005 at Tottori Sand Dune Coast. In this project, the deposition sands at harbor and river mouth were transferred to the erosion area and injected in the region of the offshore area and the land area (Figure 1).

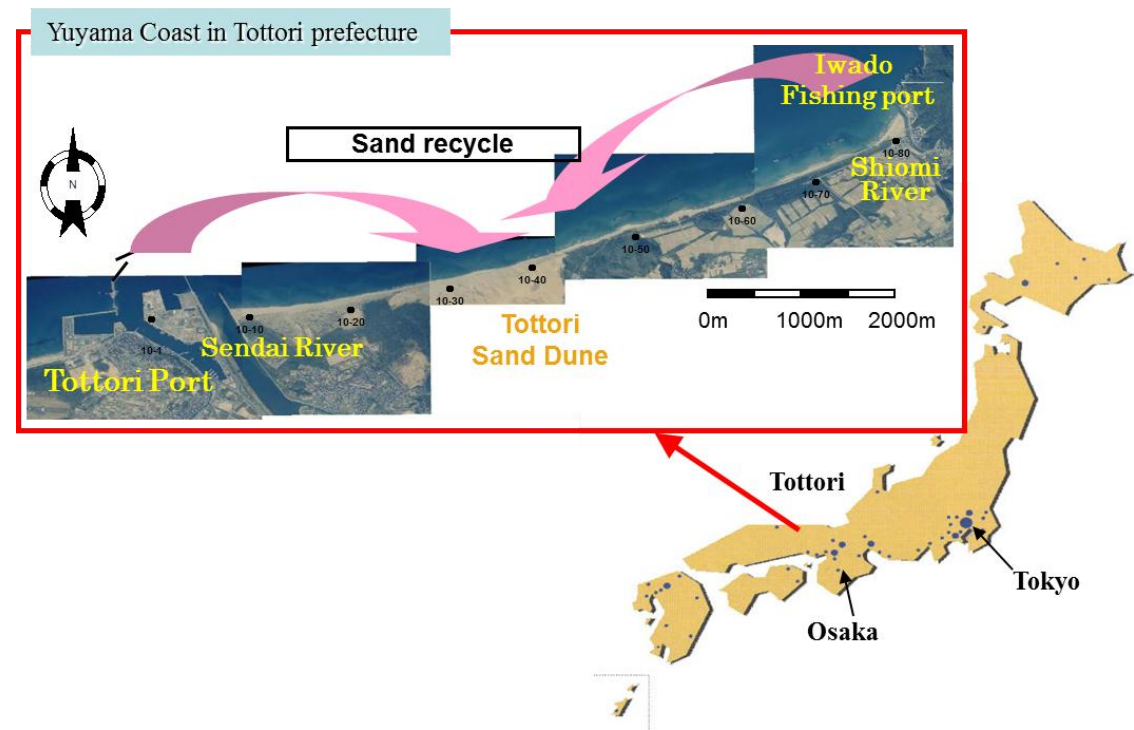

Fig.1 The sand bypass project at Yuyama coast in Tottori prefecture of Japan

\footnotetext{
${ }^{1}$ Disaster Prevention Research Institute Kyoto University, Gokasho, Uji, Kyoto, 611-0011, Japan

2 Tottori University, Civil Engineering, 4-101, Koyamacho-minami, Tottori, 680-8552, Japan

2 Tottori University, Civil Engineering, 4-101, Koyamacho-minami, Tottori, 680-8552, Japan

${ }^{3}$ NEWJEC Inc., 2-3-20, Honsho-higasi, Kitaku, Osaka, 531-0074, Japan
} 
However the beach profile has not stabled because the fine sands flow quickly. Also, as the Yuyama coast facing the Sea of Japan in Tottori Prefecture tends to repeat seasonal variation, that is, the shoreline is eroded from the autumn to the winter and is restored between spring and summer such as Figure 2. The erosion profile in Winter and accretion profile in Summer at same place show in Photo 1.

Therefor in this study, in order to investigate the effect of the coarser sand with the seasonal change, the experiment were executed for the beach profile change induced by the combination of wave type after beach nourishment.

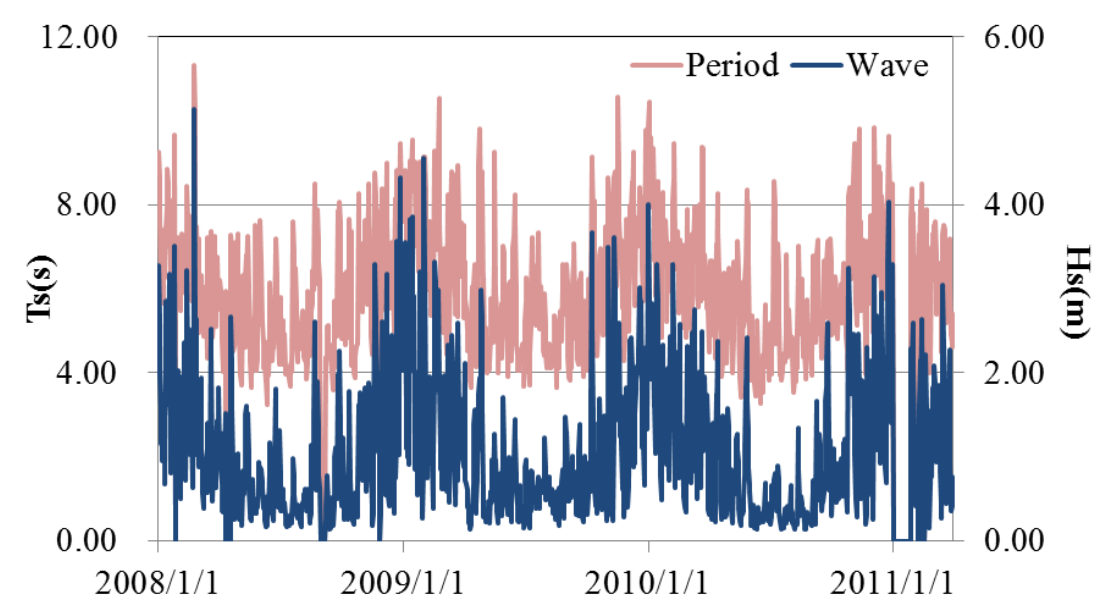

Figure 2 The time variation of the significant wave height and period measured at Yuyama coast
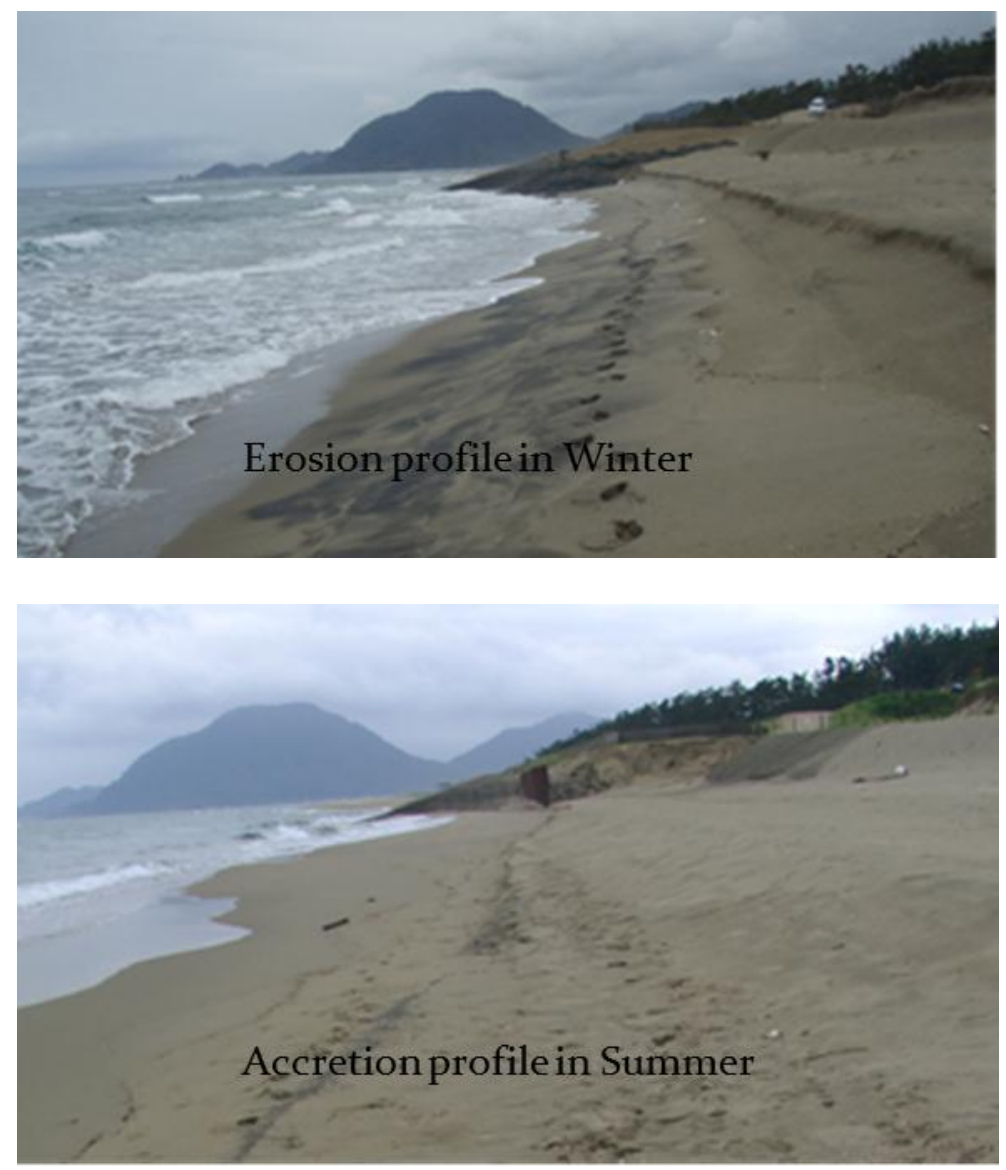

Photo 1 The beach profiles in Winter and Summer at same place 


\section{LABORATORY EXPERIMENTS}

The laboratory experiments were conducted in a two-dimensional wave flume. The glass-wall wave flume was $25.0 \mathrm{~m}$ in total length, $0.6 \mathrm{~m}$ in width and $0.6 \mathrm{~m}$ deep as shown in Figure 3. The slope of a movable bed at the end of the flume was $1 / 10$ and the layer (thickness of the sand bed) was $15 \mathrm{~cm}$. The median grain size of the sand was $0.23 \mathrm{~mm}$. For the beach nourishment, three types of the grain size were used. The types of grain size are listed in Table 1.

In this experiment, the two types of irregular wave conditions are introduced, such as the erosion type and the accretion type condition listed in Table 2.

The wave types were selected by $C$ parameter suggested by Sunamura and Horikawa (1974) as shown in Eq. (1).

$$
C=\frac{H o / L o(\tan \beta)^{0.27}}{\left(d_{50} / L o\right)^{0.67}}
$$

where, and are the wave height and length in deep water. Tan $\beta$ is the gradient of sea bottom. $d_{50}$ is the median diameter of the sand. And the relationship between $C$ parameters and beach profiles is listed in Table 3.

The beach profile was measured by laser displacement meter, and the neighborhood of the run-up area was photographed using the fixed point camera.

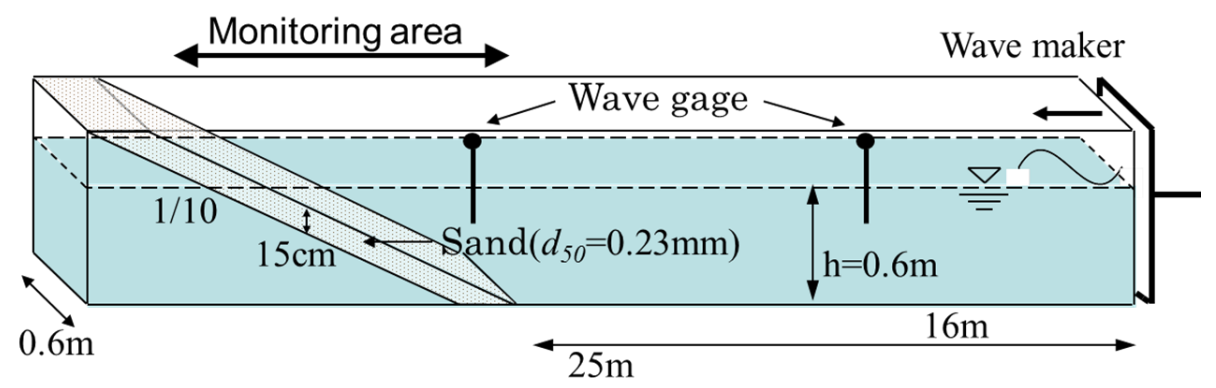

Figure 3 Experimental Set-up

\begin{tabular}{|c|c|c|c|}
\hline \multicolumn{4}{|c|}{ Table 1. The types of grain size } \\
\hline & Case1 & Case2 & Case3 \\
\hline$d_{50}$ & $0.23 \mathrm{~mm}$ & $0.70 \mathrm{~mm}$ & $3.75 \mathrm{~mm}$ \\
\hline
\end{tabular}

\begin{tabular}{|c|c|c|}
\hline \multicolumn{3}{|c|}{ Table 2. Wave conditions } \\
\hline & Erosion type & Accretion type \\
\hline$H_{1 / 3}(\mathrm{~cm})$ & 8.34 & 4.20 \\
\hline$T_{1 / 3}(\mathrm{~s})$ & 0.89 & 2.10 \\
\hline $\mathrm{C}$ & 11.47 & 3.72 \\
\hline
\end{tabular}

\begin{tabular}{|c|c|c|c|}
\hline \multicolumn{4}{|c|}{ Table 3. } \\
\hline & $\begin{array}{c}\text { Accretion } \\
\text { type }\end{array}$ & $\begin{array}{c}\text { Intermediat } \\
\text { e type }\end{array}$ & $\begin{array}{c}\text { Erosion } \\
\text { type }\end{array}$ \\
\hline Laboratory & $4>C$ & $8>C>4$ & $C>8$ \\
\hline Field & $9>C$ & $18>C>9$ & $C>18$ \\
\hline
\end{tabular}




\section{LABORATORY TESTS}

\section{Morphological change by the combination of the wave condition}

The experiment for beach profile changes induced by combination of the wave type, such as erosional wave or accretional wave after beach nourishment was executed.

First, the equilibrium bottom topography of the bar type (erosion type) was made by the action of the erosion wave during 10 hours. Then in order to examine of the effect of the beach nourishment, the sand volume of $0.01 \mathrm{~m}^{3}$ were injected at the offshore breaking point. After that the wave of the step type (accretion type) was acted.

The temporal changes of the beach profile with the seasonal change after the beach nourishment and non-nourishment are shown in Figure 4. In Case1 and Case2, the bar disappears by successive accretion wave and the injected sands are diffused with progress of the time (Figure 4(a), Figure 4(b)). On the other hand, in Case3, some of the injected sands were kept at the injection point. Also, in Case of non-nourishment, the shoreline was advanced by accretion wave. In all cases, the shoreline moves seaward with progress of the time, but the growth process of the shoreline and the berm are different.

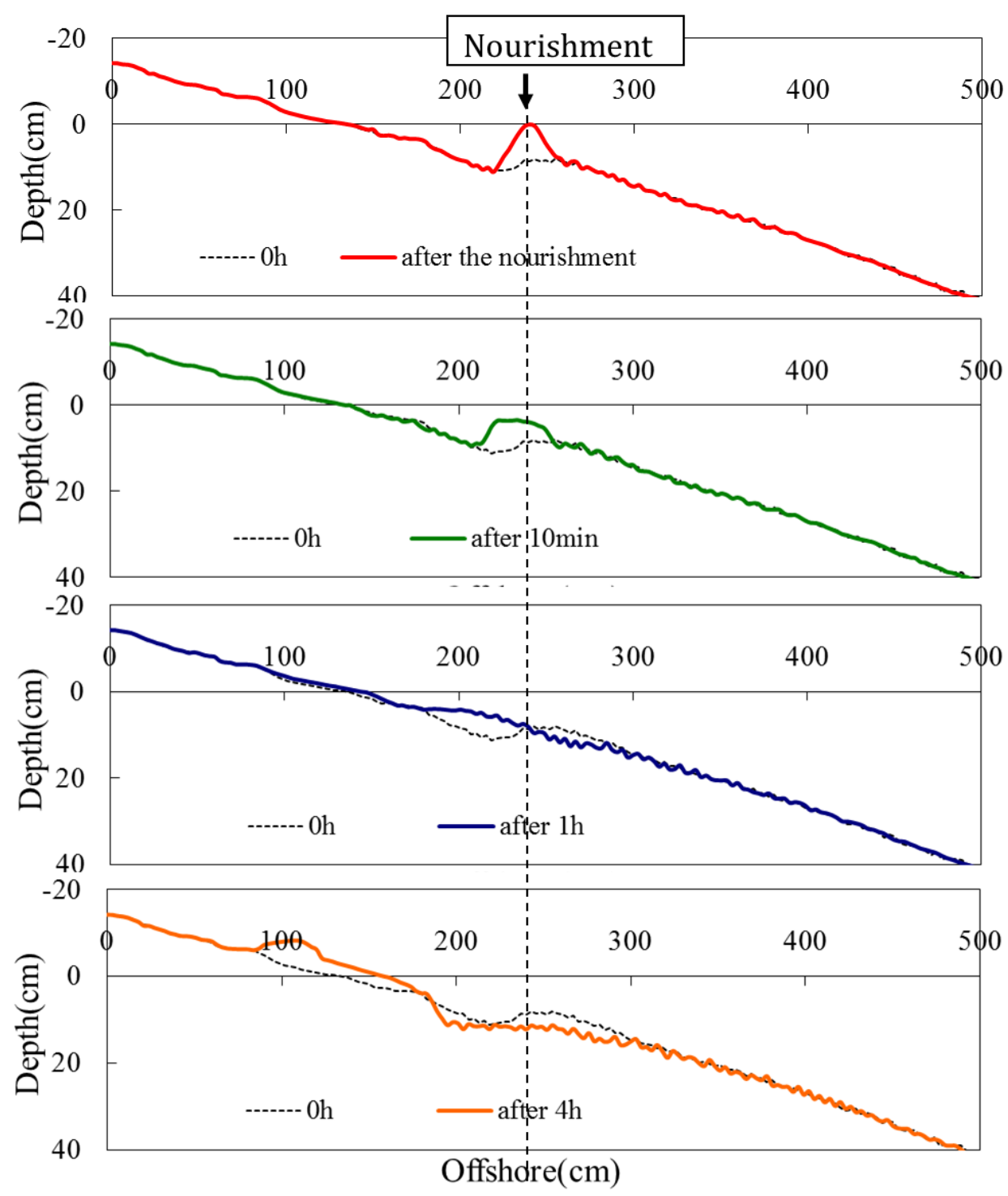

Figure 4(a) The beach change after the nourishment in Case1 


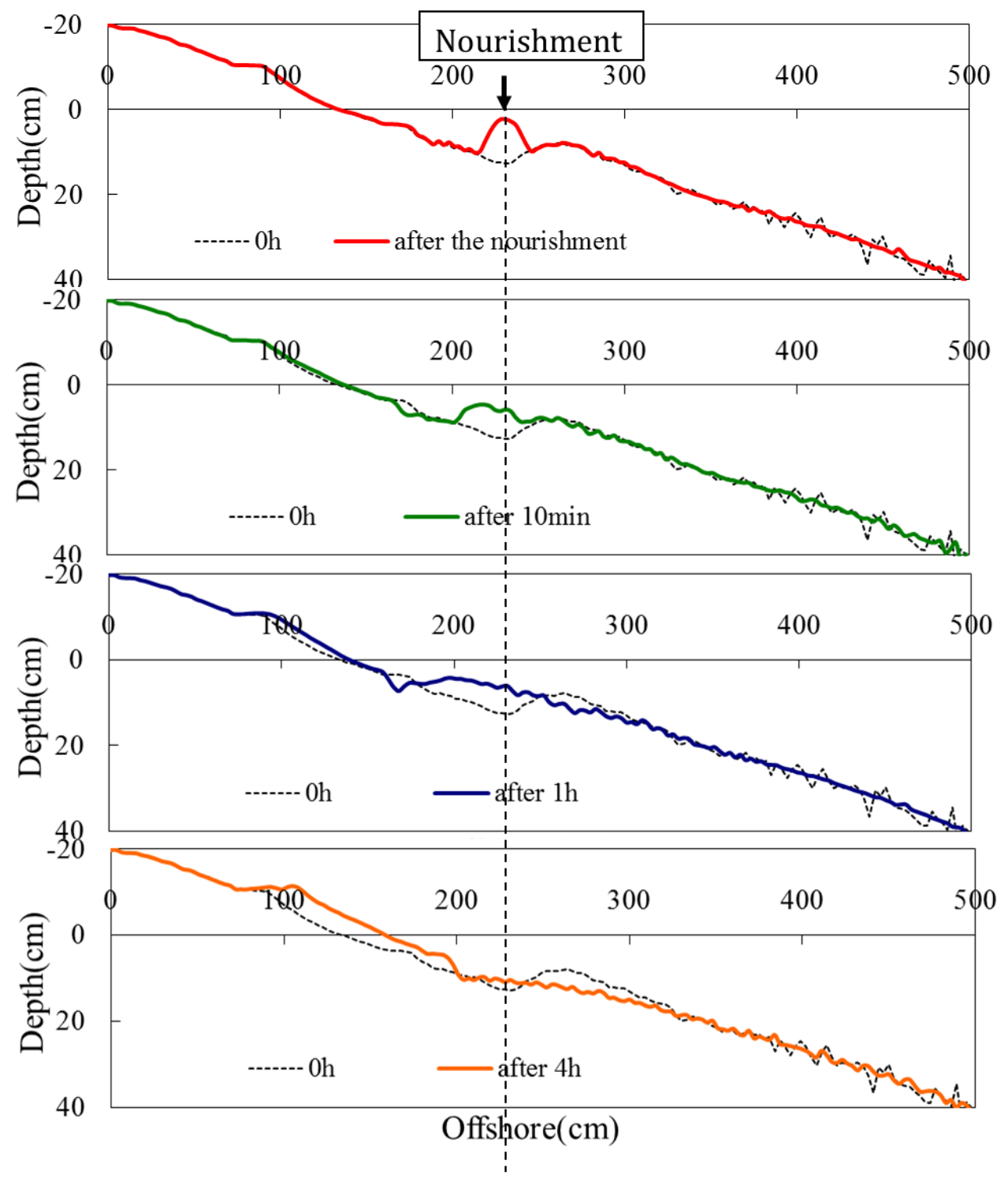

Figure 4(b) The beach change after the nourishment in Case2 


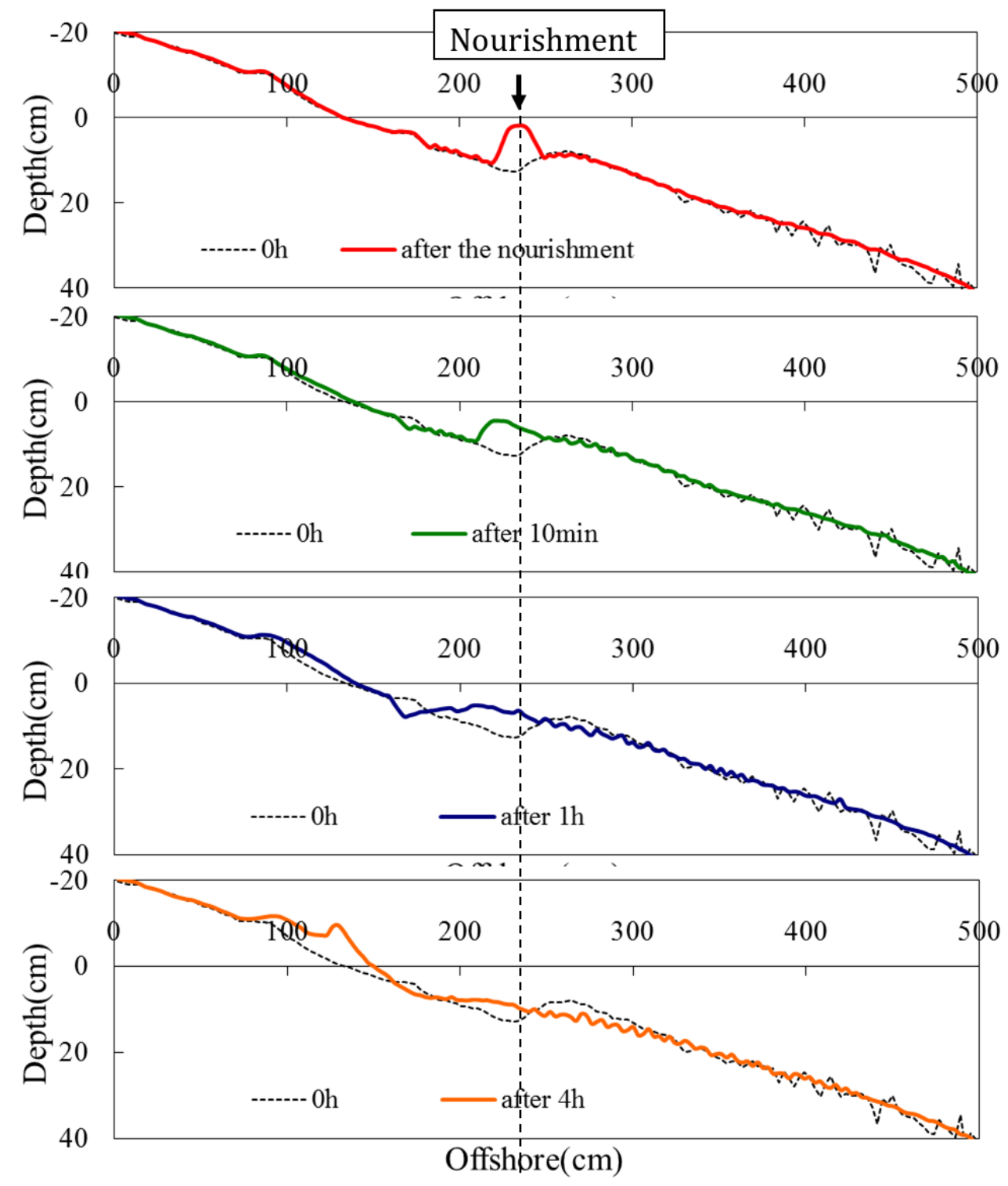

Figure 4(c) The beach change after the nourishment in Case3 


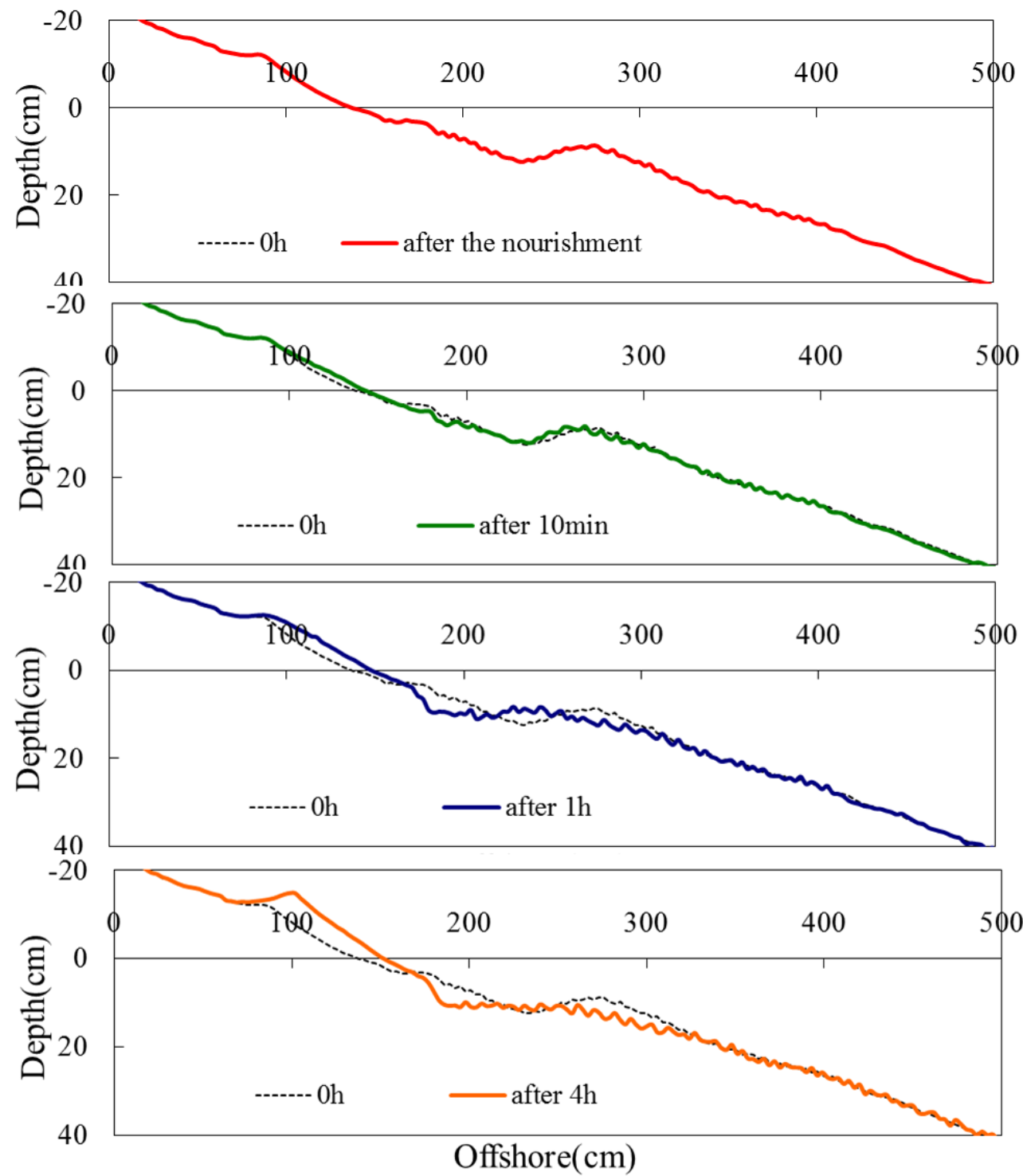

Figure 4(d) The beach change after accretional wave action under the non-nourishment 
The temporal variations of the shoreline change after the beach nourishment are shown in Figure 5. In all cases the shoreline change restored (for the accretion waves) after 240mins (4 hours). In Case 1 it was advanced rapidly after 60mins. After that the movement becomes gradually slow. On the other hand, in Case 2 and Case 3 the movement did not decrease after 4 hour. It is seems that more restoration of the shoreline are expected. From this figure, it is confirmed the coarser sand nourishment is more effective than fine sand nourishment.

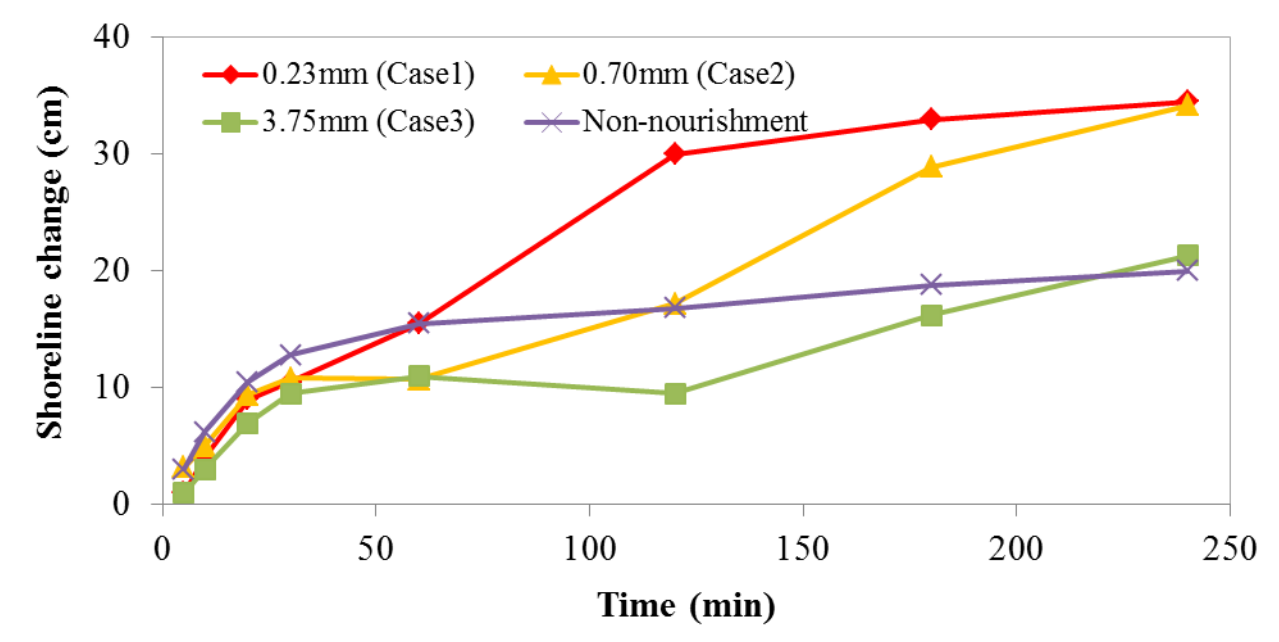

Figure 5 The time variation of the shoreline changes

The sediment transport rates from 1 to 3hours shows in Figure 6. From this figure the volume of the sediment transport correspond to the shoreline change. These results lead to the conclusion that the beach nourishments were found to be more effective under the accretion waves and using the coarser sands can be expected continuous of the effect.

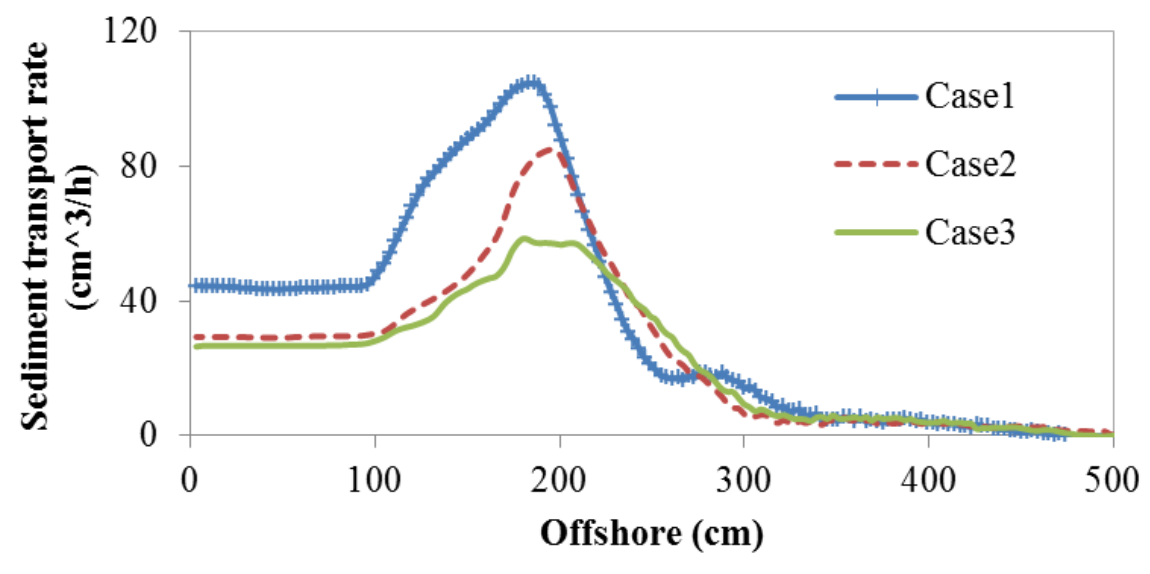

Figure 6 The sediment transport rates from 1 to 3 hours 


\section{Influences of the coarser sand nourishments under the erosion wave}

Finally, influences of the coarser sand nourishments under the erosion wave were investigated. After the wave was acted during 10 hours for equilibrium condition, the fill sand for the nourishment was injected at the offshore breaking point and the volume of the sand was $0.01 \mathrm{~m}^{3}$. And the same wave (erosion type) was acted.

The temporal variations of the beach profiles are shown in Figure 7. In Case1, the finer filled sands (the diameter of the sand is $0.23 \mathrm{~mm}$ ) were diffused rapidly with time. On the other hand, in the result of Case 2 and Case3, it is confirmed some of the filled sands were kept at the injection point after progress for several hours. However the movement of the shoreline changes was not clear.

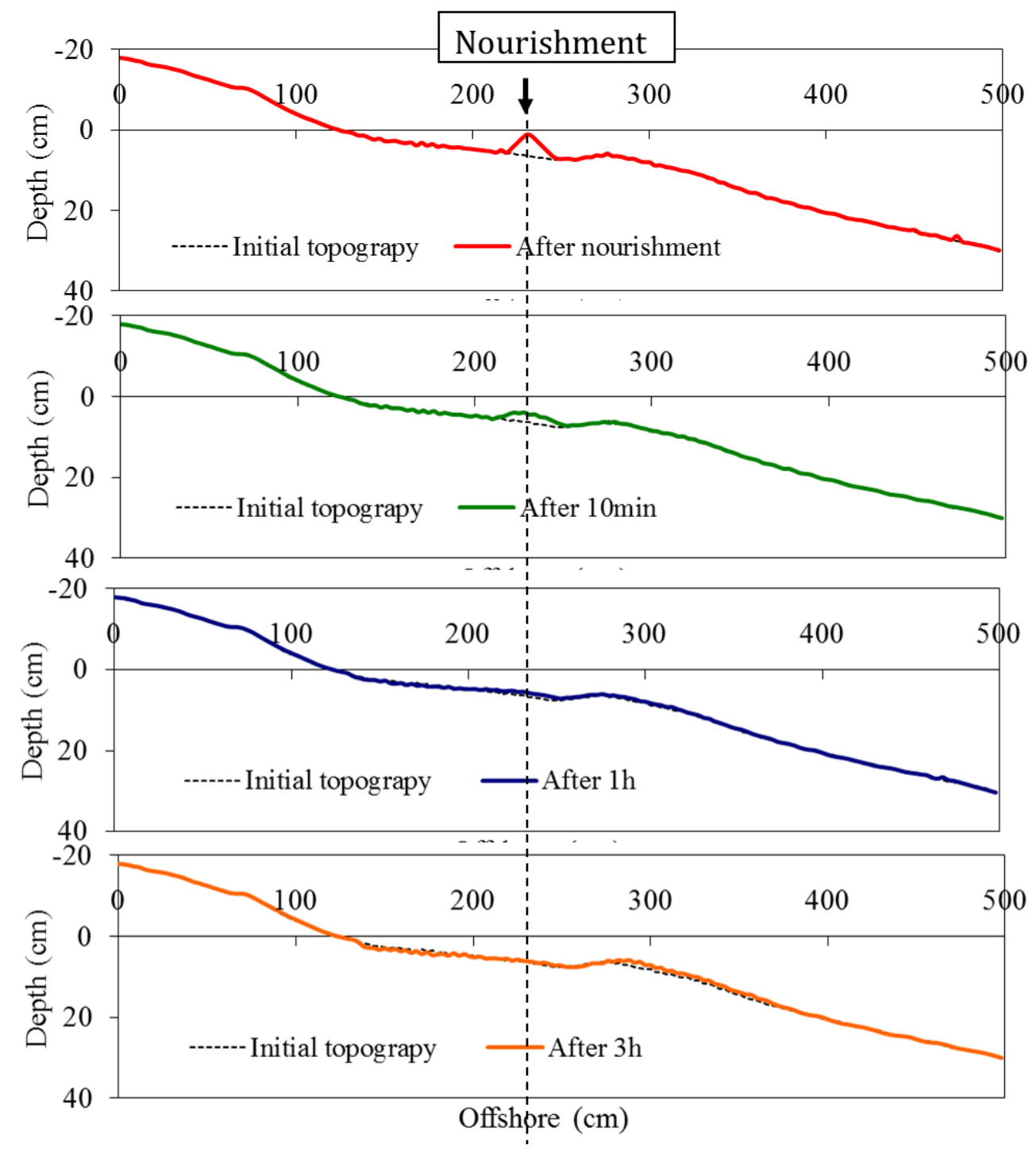

Figure 7(a) The beach change after the nourishment in Case1 


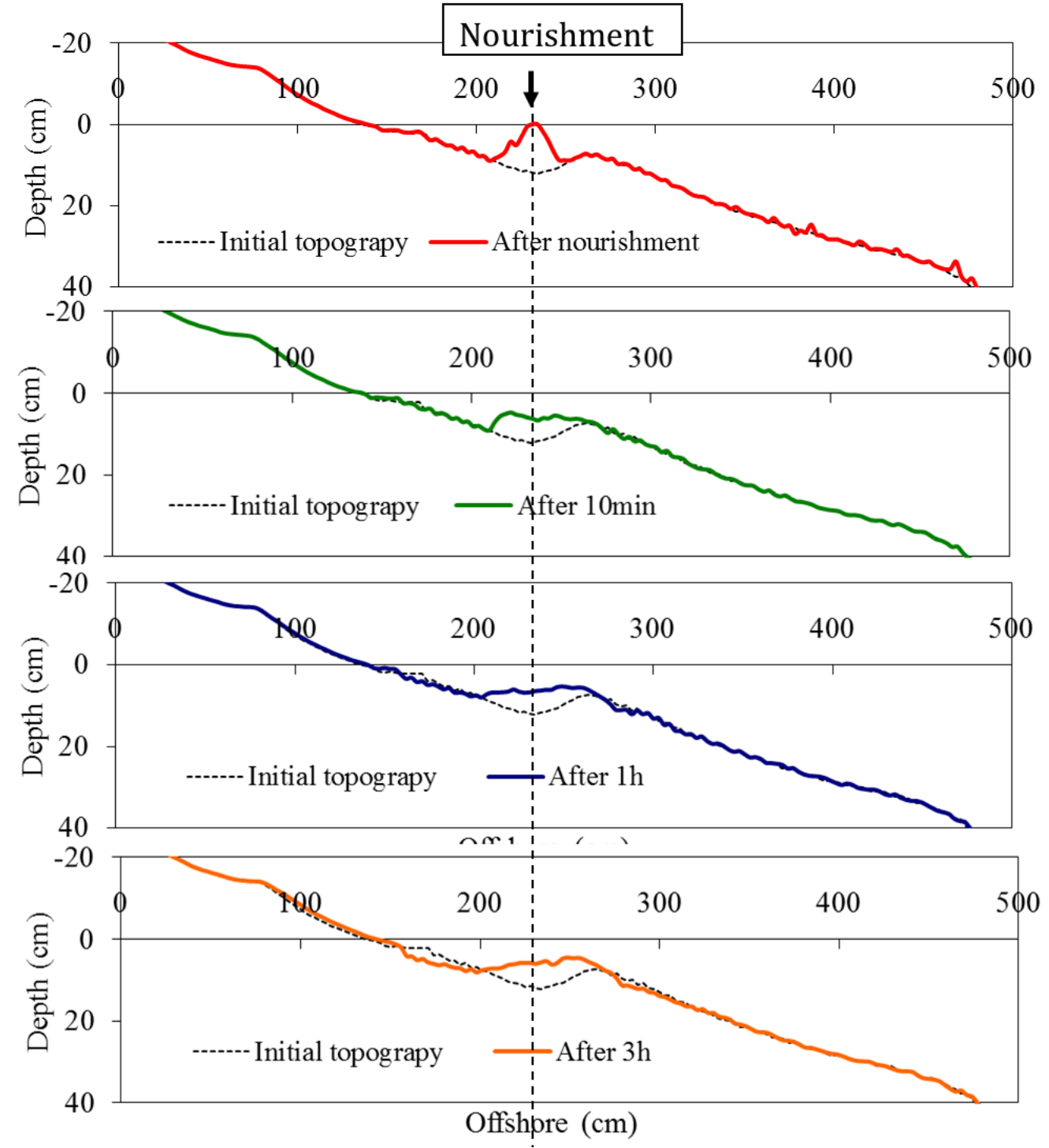

Figure 7(b) The beach change after the nourishment in Case2 


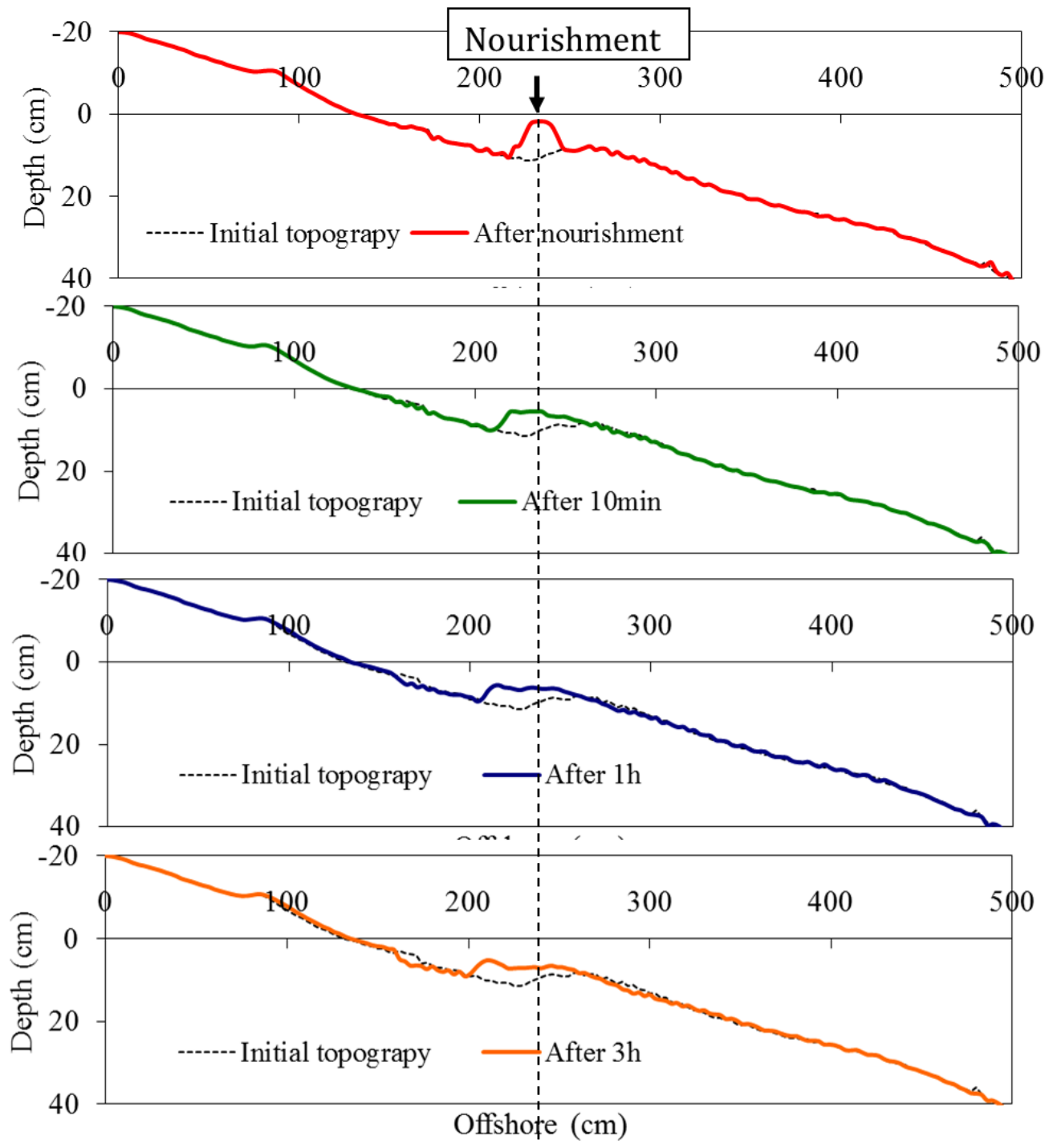

Figure 7(c) The beach change after the nourishment in Case3 
The temporal variations of the shoreline change after the nourishment show in Figure 8. In spite of an erosional wave was acted, the coarser sand nourishment can decrease the erosion. In Case1 (fine sand nourishment), the shoreline change advanced from the wave action start for the fine filled sand. However it was retreated with progress of the time. In Case2, the shoreline was retreated temporarily and it was restored progress of the time. The shoreline of Case 3 was moved seaward gradually, afterwards it was returned to the original position. The cross-shore movement of the shoreline was influenced by the size of the nourished sand.

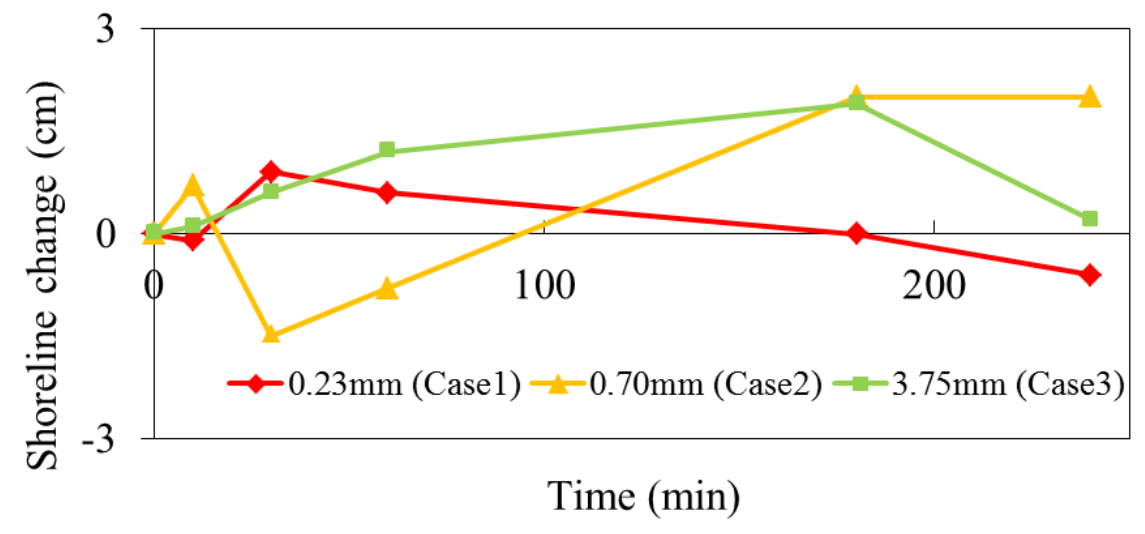

Figure 8 The temporal variations of the shoreline change after the nourishment under the erosion wave

The pictures of the filled sand after 5minuies and 1hour for Case2 (the median grain size is $0.70 \mathrm{~mm}$ ) and Case 3 (median grain size is $3.75 \mathrm{~mm}$ ) are shown in Figure 9 and Figure 10. From Figure 9 , the filled sand smoothed with the movable bed progress of the time. Therefore the shoreline moved seaward and the effect of the nourishment were lasted. On the other hand, in Case3, the filled sands were not smoothed with time for coarser filled sand. It was thought that it caused the shoreline retreated gradually.

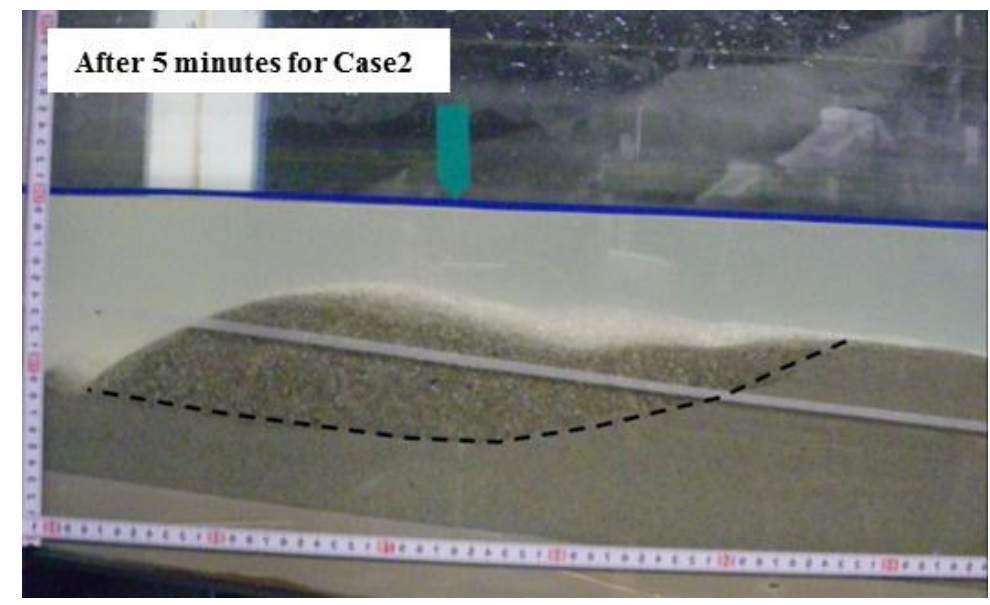

Figure 9 (a) The filled sand after 5 minutes starting wave action in Case2 


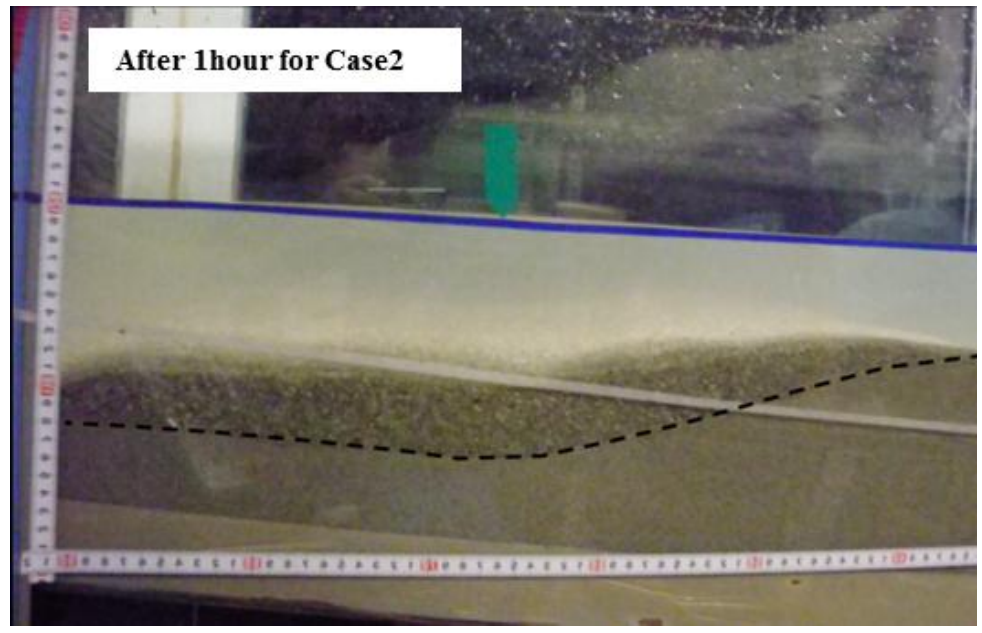

Figure 9 (a) The filled sand after 1 hour starting wave action in Case2

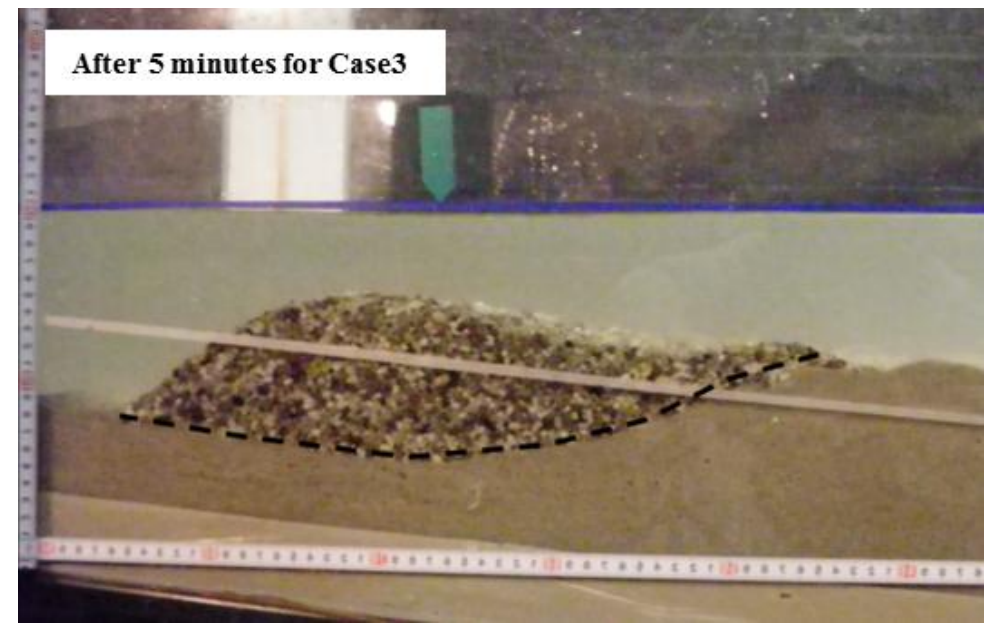

(a)After 5 minutes

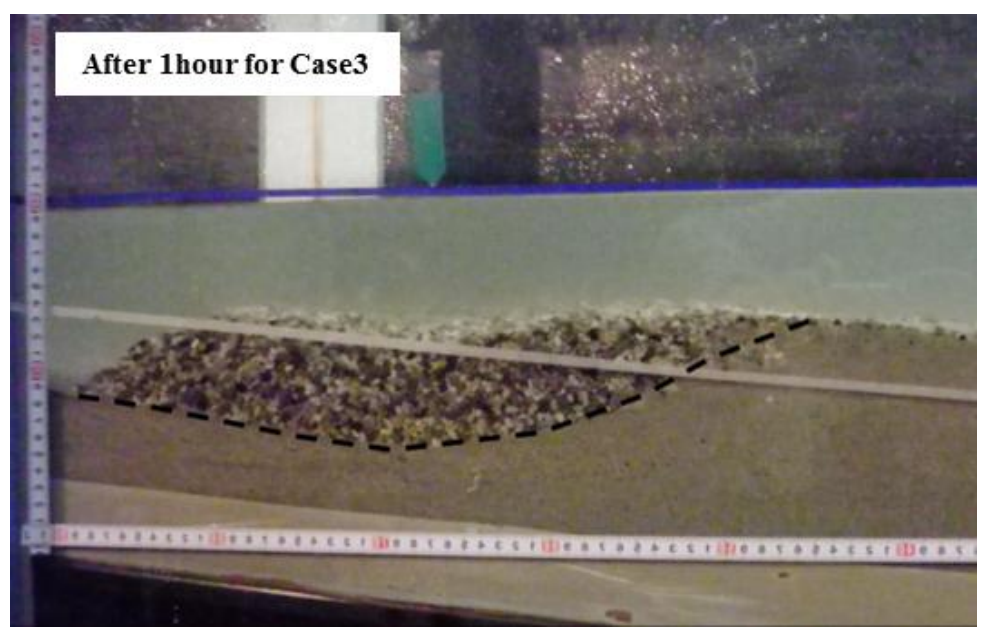

(b) After 1 hour

Figure 10 The filled sand after the wave action in Case3 
The $C$ parameter for the nourished sand shows in Figure 11. The wave type of the legend corresponds to movable bed $\left(d_{50}=0.23 \mathrm{~mm}\right)$. From this figure, it was found that the erosion wave changed into the accretion wave in case of coarser sand. Therefore while the effect of the nourishment lasts, it is possible that the wave type classify by $C$ parameter for the nourished sand. And the

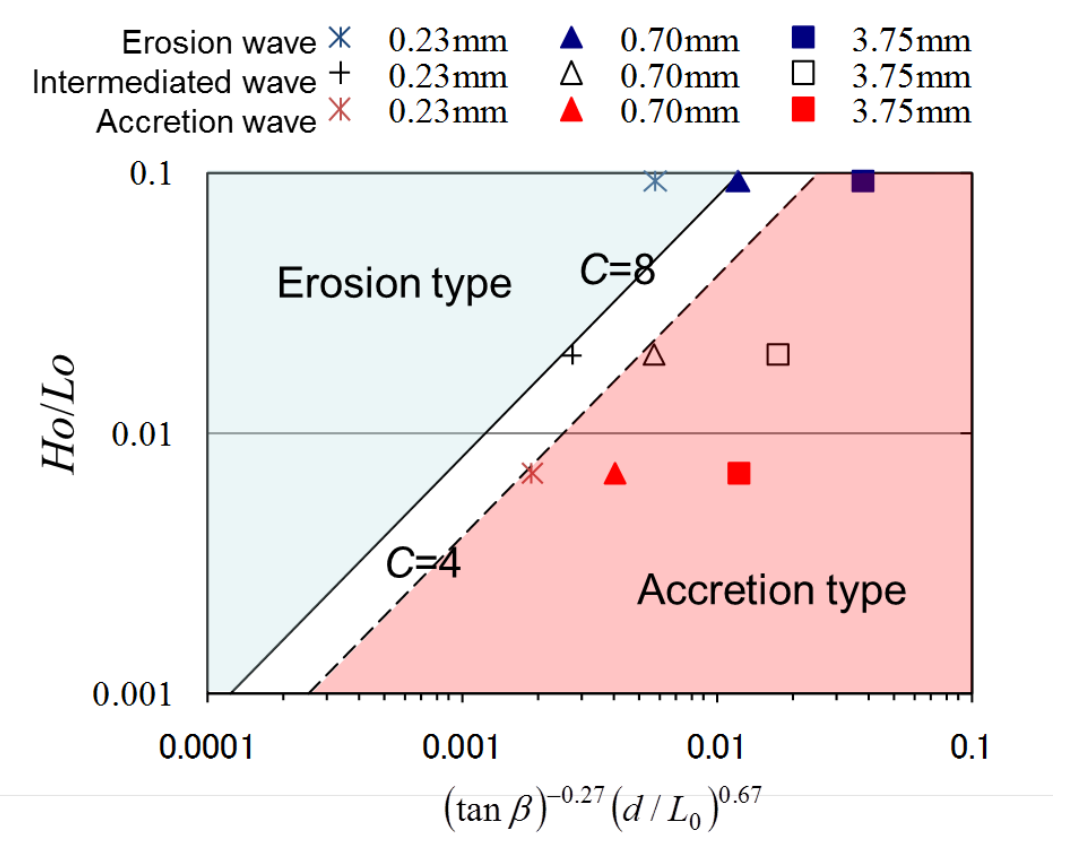

Figure 11 The $C$ parameter for the nourished sand

\section{CONCLUSIONS}

At Tottori Sand Dune Coast in Tottori prefecture of Japan, the coastal erosion has been serious problems and the beach nourishment using the coarser sand are examined for the stabilization of the beach profile. However the effects of the nourishment using the coarser sand are not clarified.

Therefor in this study, the effect of the beach nourishment with seasonal change using the coarser sand was investigated by the laboratory experiment. And the influences of the coarser sand nourishments under the erosion wave were examined.

From morphological change by the combination of the wave condition

It was confirmed that the shorelines were restored in all cases by accretion wave action. And the beach nourishments were found to be more effective under the accretion waves and using the coarser sands can be expected continuous of the effect

From influences of the coarser sand nourishments under erosion wave

In spite of an erosional wave was acted, the coarser sand nourishment can decrease the erosion. And under the wave action of the erosion type, the wave changed to an accretion type using the coarser sand. Therefor the coarser sand nourishment was effective against beach erosion. 


\section{REFERENCES}

Sunamura, T., and Horikawa, K. 1974. Two-dimensional beach transformation due to waves, Proceedings of $14^{\text {th }}$ International Conference on Coastal Engineering, pp920-938.

Shibutani, Y., Matusbara, Y., Kuroiwa, M. and Yao, N. 2011. Experimental Studies on the Effect of the Injected Sands after the Beach Nourishments, Journal of Coastal Research, Special Issue, 64, pp.588-592

Shibutani, Y., Matusbara, Y., Kuroiwa, M. and Yao, N. 2011. Experimental Study on effect of the beach nourishment using the coarser sand, Proceedings of the Sixth International Conference on Asian and Pacific Coasts, pp.275-282 